\title{
To study association of Neutrophil- Lymphocyte ratio with vascular complications in Type-2 Diabetes
}

\author{
Shilpa Tumkur Andane Gowda', Shahari Hegde Kusumakar², \\ Raveendra Kodur Ramamurthy ${ }^{3}$, Rohith Maraludevanapura Govindaiah ${ }^{4}$ \\ ${ }^{1}$ Senior Resident, ${ }^{2,4}$ Post-Graduate Trainee, ${ }^{3}$ Professor, Department of General Medicine, Bangalore Medical College \\ and Research Institute, Bangalore, Karnataka, India
}

Background: Diabetes is a pro-thrombotic state associated with increased risk of atherosclerosis and inflammation. Neutrophil lymphocyte ratio (NLR) provides information about early and subclinical inflammation and thus may act as a prognostic marker for vascular complications in type 2 diabetes. Aims and Objective: To analyze the correlation between Neutrophil- Lymphocyte ratio in diabetics with and without vascular complications. Materials and Methods: A total of 111 patients admitted in Victoria hospital and Bowring \& Lady Curzon hospital attached to Bangalore Medical College and Research Institute from NOV 2018 to MAY 2020 were studied. The data was collected according to the proforma in terms of history, clinical examination and the necessary investigations. NLR was observed in type 2 diabetic patients and was compared in those with complications and without complications. Results: The NLR was higher in diabetics with vascular complications compared to those without complications, $2.8 \pm 0.7 \mathrm{fl}$ versus $6.8 \pm 3.1 \mathrm{fl}(\mathrm{P}<0.001)$, respectively. In this study, Mean N (\%), In No Vascular Complications was $61.7 \pm 10.6$ and with vascular complications was $79.9 \pm 9.5$. Mean $L(\%)$ in No Vascular Complications was $23.7 \pm 5.8$. Mean N (\%), In No Vascular Complications was $61.7 \pm 10.6$ and with vascular complications was $79.9 \pm 9.5$. There was a significant difference in mean $\mathrm{N}(\%)$ mean $L(\%)$ and NLR in comparison with respect to Complications. Conclusion: This study showed significantly higher NLR in diabetic patients with vascular complications. Hence, NLR can be used as a simple parameter to assess the vascular complications in diabetes.

\section{Access this article online}

\section{Website:}

http://nepjol.info/index.php/AJMS

DOI: 10.3126/ajms.v12i8.36161

E-ISSN: 2091-0576

P-ISSN: 2467-9100

Copyright (c) 2021 Asian Journal of Medical Sciences

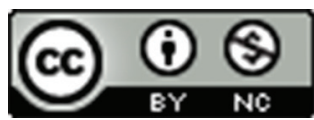

This work is licensed under a Creative Commons Attribution-NonCommercial 4.0 International License.

Key words: Neutrophil- Lymphocyte ratio; Type-2 Diabetes; Vascular complications

\section{INTRODUCTION}

Type 2 diabetes mellitus has become a serious threat to global human health because of its vascular complications which are associated with increased disability, frailty and reduced life expectancy, including cardiovascular and cerebrovascular diseases(CVD), diabetic nephropathy, diabetic retinopathy, diabetic foot. ${ }^{1-3}$ India is the diabetes capital of the world, with diabetes and pre-diabetes, prevalence of $9 \%$ and $11-14 \%$, respectively. ${ }^{4}$ This increased burden of diabetes in Indians is a grim precursor of an exponential increase in diabetes-related end-organ damage and associated morbidity in the next few decades. There is an urgent need for cheap and easy to measure predictors of the occurrence of diabetes related end-organ damage in Indians. This would help in preventing vascular complications in specific individuals to improve long term clinical outcomes.

Chronic inflammation has been considered the potential pathogenesis responsible for the development of diabetic complications. ${ }^{5-7}$ Increased white blood count (WBC) is a easily available inflammatory marker, which correlates with several cardiovascular disease risk factors and its sequel with diabetes. ${ }^{8-11}$ Apart from WBC count, inflammatory markers 
such as interleukin 1(IL-1), IL-6, IL-8, transforming growth factor $\beta 1$, tumor necrosis factor-a have been linked to end organ damage in diabetes. ${ }^{12-16}$ Limitations of these markers include lack of availability in routine clinical practice compounded by the associated increased expenses and assay standardization. ${ }^{17,18}$ Among multiple parameters complete blood count, neutrophil lymphocyte ratio (NLR) has been studied extensively for the association with cardiovascular risk factors like myocardial infarction, heart failure and stroke. ${ }^{19,20}$ NLR stands out as a novel marker of chronic inflammation that reflects a balance between 2 complementary components of the immune system- Neutrophils being the active nonspecific mediator of inflammation, whereas Lymphocytes acting as the protective or regulatory component of inflammation. ${ }^{21,22}$ Data are lacking of NLR as a predictor of end-organ damage in Indians with T2DM. This study, therefore, aimed to evaluate the role of NLR has a role in predicting diabetic vascular complications such as retinopathy, neuropathy, nephropathy, diabetic foot, cardiovascular and cerebrovascular complications.

Aims and objectives

To compare Neutrophil-Lymphocyte ratio in diabetics with and without vascular complications.

\section{MATERIALS AND METHODS}

\section{Study design}

Cross sectional type.

\section{Study area}

The present study was conducted on patients admitted in hospitals affiliated to Bangalore Medical College and Research Institute, Bangalore.

\section{Inclusion criteria}

1. Age $>18$ years

2. Patient willing to give informed consent

3. Diagnosis as per American diabetes association 2018 guidelines $^{23}$

\section{Exclusion criteria}

1. Patients who did not give informed consent

\section{Study population}

A study population of 111 diabetic patients with and without vascular complications was taken with 56 patients with complications and 55 without complications.

\section{Study period}

November 2018 to May 2020.

\section{Methodology of data collection}

This study was conducted among patients admitted under medicine department between November 2018 to May 2020 at Victoria hospital and Bowring \& Lady Curzon hospital, Bangalore Medical College and Research Institute, Bangalore, Karnataka, India. Approval and clearance were obtained from the institutional ethics committee on 15/11/2018-BMCRI/PG/124/2018-19. Information was collected from the patients on their duration of T2DM, treatment history, age and sex. Data were collected on the anthropometric parameters and vitals of the patients (height, weight, BMI), Pulse rate and Blood pressure. Both fasting and post prandial blood samples of $5 \mathrm{ml}$ each were collected in plain vacutainer and processed immediately for routine biochemical analysis. Spot urine sample was collected and looked for presence of albuminuria. Such patients underwent ultrasonography abdomen for the evaluation of the kidney echotexture and size. Digital fundoscopy was done to assess diabetic retinopathy. Diabetic retinopathy was diagnosed using The Early Treatment Diabetic Retinopathy Study criteria (ETDRS). ${ }^{24}$ Patients who had neuropathic symptoms were clinically examined for diabetic neuropathy. Patients who had symptoms and signs of lower limb ischemia were evaluated with respective limb arterial and venous doppler. Patients were screened and evaluated clinically for macrovascular complications and relevant investigations like ECG, 2D ECHO for cardiovascular complications and neuroimaging for cerebrovascular complications. All relevant investigations were done on out-patient and in-patient basis.

\section{STATISICAL ANALYSIS}

\section{Statistical methods}

Data was entered into Microsoft excel data sheet and was analyzed using SPSS 22 version software. Categorical data was represented in the form of Frequencies and proportions. Chi-square test was used as test of significance for qualitative data. Continuous data was represented as mean and standard deviation. Independent $t$ test was used as test of significance to identify the mean difference between two quantitative variables. ANOVA (Analysis of Variance) was the test of significance to identify the mean difference between more than two groups for quantitative data.

\begin{tabular}{lcc}
\multicolumn{3}{l}{ Table 1: Age distribution of subjects in the study } \\
\hline Age & Count & $\%$ \\
\hline$<40$ years & 17 & $15.3 \%$ \\
41 to 50 years & 27 & $24.3 \%$ \\
51 to 60 years & 27 & $24.3 \%$ \\
61 to 70 years & 25 & $22.5 \%$ \\
71 to 80 years & 11 & $9.9 \%$ \\
$>80$ years & 4 & $3.6 \%$ \\
\hline
\end{tabular}


Table 2: Glycemic Profile of subject's comparison with respect to duration of diabetes

\begin{tabular}{|c|c|c|c|c|c|c|c|c|c|c|c|}
\hline & \multicolumn{10}{|c|}{ Duration of Diabetes } & \multirow[t]{3}{*}{$P$ value } \\
\hline & \multicolumn{2}{|c|}{ Newly Detected } & \multicolumn{2}{|c|}{$<5$ years } & \multicolumn{2}{|c|}{6 to 10 years } & \multicolumn{2}{|c|}{$>10$ years } & \multicolumn{2}{|c|}{ Total } & \\
\hline & Mean & SD & Mean & SD & Mean & SD & Mean & SD & Mean & SD & \\
\hline FBS (mg/dl) & 202.77 & 70.93 & 242.5 & 85.35 & 230.44 & 74.6 & 249.41 & 57.67 & 233.42 & 77.12 & 0.13 \\
\hline PPBS (mg/dl) & 265.67 & 63.67 & 281.38 & 78.14 & 276.29 & 92.39 & 285.82 & 62.58 & 277.95 & 78. 87 & 0.55 \\
\hline $\mathrm{HbA} 1 \mathrm{c}(\%)$ & 9.42 & 1.56 & 9.86 & 1.93 & 9.58 & 2.1 & 9.34 & 2.09 & 9.63 & 1.97 & 0.45 \\
\hline
\end{tabular}

\begin{tabular}{|c|c|c|c|c|c|c|c|c|c|c|c|}
\hline & \multicolumn{10}{|c|}{ Duration of Diabetes } & \multirow[t]{3}{*}{$P$ value } \\
\hline & \multicolumn{2}{|c|}{ Newly Detected } & \multicolumn{2}{|c|}{$<5$ years } & \multicolumn{2}{|c|}{6 to 10 years } & \multicolumn{2}{|c|}{$>10$ years } & \multicolumn{2}{|c|}{ Total } & \\
\hline & Mean & SD & Mean & SD & Mean & SD & Mean & SD & Mean & SD & \\
\hline N (\%) & 68.25 & 6.89 & 68.93 & 12.41 & 71.85 & 12.93 & 62.32 & 11.93 & 70.9 & 12.6 & 0.035 \\
\hline L (\%) & 20.92 & 6.44 & 18.80 & 7.84 & 19.12 & 9.77 & 21.66 & 7.21 & 19.0 & 8.1 & 0.128 \\
\hline NL Ratio & 3.71 & 2.39 & 4.54 & 3.40 & 5.39 & 4.04 & 3.08 & 0.75 & 4.8 & 3.0 & 0.045 \\
\hline
\end{tabular}

Graphical representation of data

MS Excel and MS word was used to obtain various types of graphs such as bar diagram, Pie diagram and ROC Curve

$\mathrm{p}$ value (Probability that the result is true) of $<0.05$ was considered as statistically significant after assuming all the rules of statistical tests.

\section{Statistical software}

MS Excel, SPSS version 22 (IBM SPSS Statistics, Somers NY, USA) was used to analyze data.

\section{RESULTS}

This study was conducted among 111 patients admitted in Victoria hospital and Bowring \& Lady Curzon hospital attached to Bangalore Medical College and Research Institute.

Age distribution

In this study Mean age was $55.66 \pm 13.675$ years (Table 1$)$.

\section{Sex distribution}

Out of 111 patients 63 patients (56.8\%) were Male and 48 patients $(43.2 \%)$ were Female. In this study male patients were more than female.

Distribution of cases according to duration of diabetes In the study, duration of diabetes was newly detected in $16.2 \%,<5$ years in $37.8 \%, 6$ to 10 years in $30.6 \%$ and $>10$ years in $15.3 \%$.

Glycemic profile of subject's comparison with respect to duration of diabetes

There was no significant correlation of FBS, PPBS and $\mathrm{HbA} 1 \mathrm{C}$ with the duration of diabetes (Table 2).

\begin{tabular}{|c|c|c|}
\hline Complications & Count & $\%$ \\
\hline No Vascular Complications & 55 & $49.5 \%$ \\
\hline Micro complications & 25 & $22.5 \%$ \\
\hline Macro complications & 32 & $28.8 \%$ \\
\hline
\end{tabular}

Correlation of NLR with respect to duration of diabetes There was significant correlation of $\mathrm{N}(\%)$ and $\mathrm{NL}$ ratio with duration of diabetes but L ( $\%)$ did not show significant correlation with duration of diabetes (Table 3).

Vascular complications in diabetic subjects

In the study patients had no vascular complications in $49.5 \%$, had micro-vascular complications in $22.5 \%$ and macro-vascular complications in $28.8 \%$. Out of which patients had Diabetic retinopathy in 34\%, diabetic nephropathy in $34.2 \%$, diabetic neuropathy in $0.9 \%$, cerebrovascular Accident in 17.1\%, ischemic heart disease in $12.6 \%$, diabetic foot in $6.3 \%$ of the individuals (Table 4).

NLR comparison with complications and glycemic profile in type 2 diabetics

In the study N (\%) was 70.9 $\pm 13.6, \mathrm{~L}(\%)$ was $19 \pm 8.1$ and NL Ratio was $4.8 \pm 3$ among subjects involved in the study.

In this study, mean $\mathrm{N}(\%)$ in no vascular complications was $61.7 \pm 10.6$, in micro complications was $80.6 \pm 9.4$ and in macro complications was $79.5 \pm 9.7$. There was a significant difference in mean $\mathrm{N}(\%)$ comparison with respect to complications.

Mean L (\%) in no vascular complications was $23.7 \pm$ 5.8 , in micro complications was $14.1 \pm 6.9$ and in macro 


\begin{tabular}{|c|c|c|c|c|c|c|c|c|}
\hline & \multicolumn{6}{|c|}{ Complications } & \multirow[t]{3}{*}{$\mathbf{F}$} & \multirow[t]{3}{*}{$P$ value } \\
\hline & \multicolumn{2}{|c|}{ No Vascular Complications } & \multicolumn{2}{|c|}{ Micro complications } & \multicolumn{2}{|c|}{ Macro complications } & & \\
\hline & Mean & SD & Mean & SD & Mean & SD & & \\
\hline $\mathrm{N}(\%)$ & 61.7 & 10.6 & 80.6 & 9.4 & 79.5 & 9.7 & 45.039 & $<0.001^{*}$ \\
\hline$L(\%)$ & 23.7 & 5.8 & 14.1 & 6.9 & 14.8 & 8.0 & 25.864 & $<0.001^{*}$ \\
\hline NL Ratio & 2.8 & 0.7 & 7.1 & 3.5 & 6.5 & 2.7 & 44.522 & $<0.001^{*}$ \\
\hline
\end{tabular}

\begin{tabular}{|c|c|c|}
\hline & & NLRATIO \\
\hline \multirow[t]{2}{*}{ NLRATIO } & $\begin{array}{l}\text { Pearson Correlation } \\
P \text { value }\end{array}$ & 1 \\
\hline & $\mathrm{N}$ & 111 \\
\hline \multirow[t]{3}{*}{ FBS (mg/dl) } & Pearson Correlation & 0.38 \\
\hline & $P$ value & .000039 \\
\hline & $\mathrm{N}$ & 111 \\
\hline \multirow[t]{3}{*}{ PPBS (mg/dl) } & Pearson Correlation & 0.49 \\
\hline & $P$ value & $<.00001$ \\
\hline & $\mathrm{N}$ & 111 \\
\hline \multirow[t]{3}{*}{ HBA1C (\%) } & Pearson Correlation & 0.29 \\
\hline & $P$ value & .002019 \\
\hline & $\mathrm{N}$ & 111 \\
\hline
\end{tabular}

\begin{tabular}{lc} 
Table 7: Validity of NLR in predicting Vascular \\
Complications \\
\hline \multicolumn{2}{l}{ Area under the ROC curve (AUC) } \\
\hline Area under the ROC curve (AUC) & 0.924 \\
Standard Error & 0.0315 \\
95\% Confidence interval & 0.858 to 0.966 \\
z statistic & 13.441 \\
Significance level P (Area=0.5) & $<0.0001$ \\
\hline Youden index & \\
\hline Youden index J & 0.8565 \\
95\% Confidence interval & 0.7326 to 0.9282 \\
Associated criterion & $>3.9989$ \\
95\% Confidence interval & 3.477203178 to 4.2334 \\
\hline
\end{tabular}

complications was $14.8 \pm 8$. There was a significant difference in mean $\mathrm{L}(\%)$ comparison with respect to complications.

Mean NL Ratio in no vascular complications was $2.8 \pm$ 0.7 , in micro complications was $7.1 \pm 3.5$ and in macro complications was $6.5 \pm 2.7$. There was a significant difference in mean NL Ratio comparison with respect to complications (Table 5, Figure 1).

In the study there was significant positive correlation between NLR and glycemic profile i.e., with increase in FBS, PPBS, HBA1C there was increase in NLR and vice versa, (Table 6).

NLR of $>3.998$ had highest sensitivity of $89.29 \%$, Specificity of $96.36 \%$, PPV of $96.2 \%$ and NPV of $89.8 \%$ in predicting vascular complications among diabetics (Figure 2, Table 8).

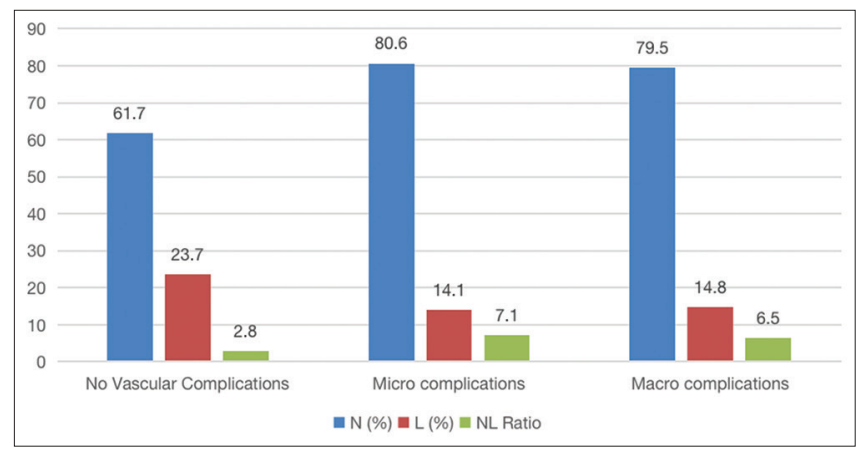

Figure 1: Bar diagram showing NLR comparison with respect to complication

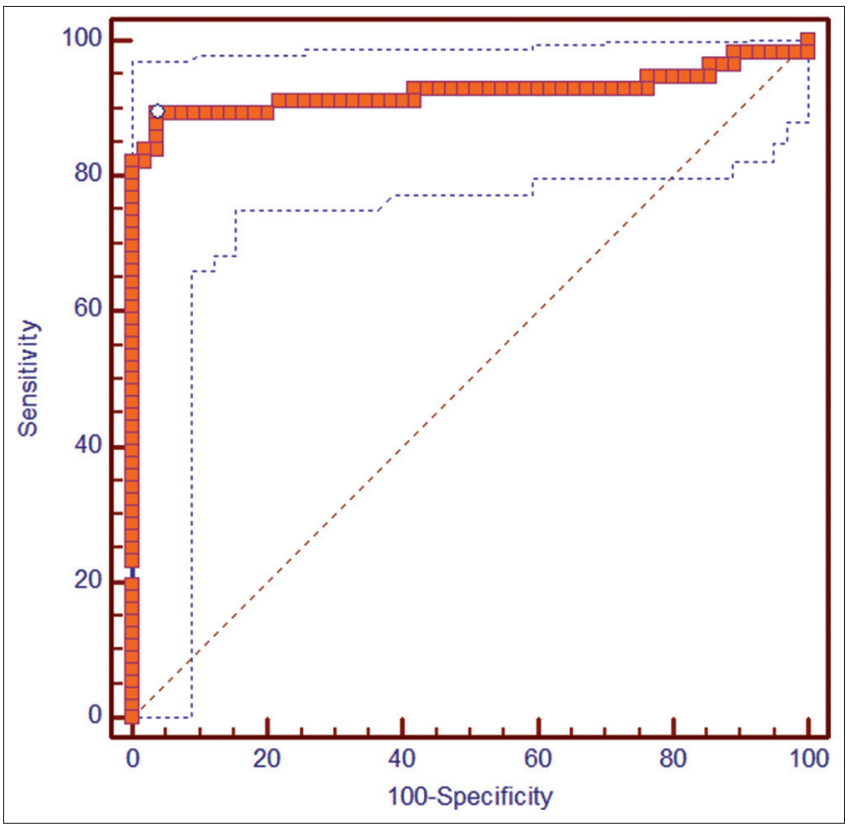

Figure 2: ROC Curve showing Validity of NLR in predicting Vascular Complications

\section{DISCUSSION}

Diabetes is a growing health problem associated with increased risk of micro and macro- vascular complications. With the easy availability of various blood tests such as complete blood count (CBC) efforts are made to identify and prove their utility to act as bio-markers for early detection of diabetic complications.

This is a cross sectional study conducted over a period of 2 years from Nov 2018- May 2020 to study association 


\section{Table 8: Criterion values and coordinates of the ROC curve}

\begin{tabular}{|c|c|c|c|c|c|c|c|c|}
\hline Criterion & Sensitivity & $95 \% \mathrm{Cl}$ & Specificity & $95 \% \mathrm{Cl}$ & $+P V$ & $95 \% \mathrm{Cl}$ & $-P V$ & $95 \% \mathrm{Cl}$ \\
\hline$>3.9989$ & 89.29 & $78.1-96.0$ & 96.36 & $87.5-99.6$ & 96.2 & $86.8-99.5$ & 89.8 & $79.2-96.2$ \\
\hline
\end{tabular}

of NLR with vascular complications in Type 2 DM. 111 patients were included in this study, where 56 patients were diabetics with vascular complication ns and 55 patients were diabetes without vascular complications.

\section{Age}

In this study the most common age group was 51-60 (22 patients) with mean age of 55.66 13.67 . Most of the patients were of 40-70 years. The IDF Diabetes Atlas which tracks the global impact of diabetes also shows the more common age group of diabetes is between 20-79 years of age. ${ }^{25}$ This is important because of increasing risk within population and failure to control factors such as obesity and poor diets. This would further cause a rising prevalence as each person getting diagnosed at a earlier age stays longer.

\section{Sex}

In this study there was male predominance i.e., 56.8\% of patients and female patients were $43.2 \%$, which was similar to study done by Mohammed Haghighatpanah et al, Correlation of glycosylated hemoglobin levels with fasting and postprandial glucose in South Indian Type 2 Diabetic patients. ${ }^{26}$

\section{Duration of diabetes}

In this study, Duration of Diabetes was Newly Detected in $16.2 \%,<5$ years in $37.8 \%, 6$ to 10 years in $30.6 \%$ and $>10$ years in $15.3 \%$. Ours being a tertiary care center most of the patients were incidentally diagnosed patients and duration more than 6 years who were on regular follow up for their medications.

There was no significance in mean FBS, mean PPBS, mean HBA1C compared with the duration of the diabetes.

In this study, Duration of diabetes had significant correlation with $\mathrm{N}(\%)$ with $\mathrm{p}$ value $(0.035)$ and $\mathrm{NL}$ ratio with p value $(0.045)$ but the $\mathrm{L}(\%)$ did not show significant correlation.

Study done by Sachin chittawar et al. showed that patients in higher NLR quartiles had significantly higher diabetes duration. $^{27}$

\section{Glycemic profile}

In this study, there was a significant positive correlation found in between NLR and FBS, NLR and PPBS and NLR and HBA1C.
Study done by Mazhar hussain et al. also showed that NLR was significantly high in diabetic patients with poor glycemic control. ${ }^{28}$

NLR with respect to vascular complications in type-2 diabetes

Study done by Moursy et al. showed NLR is an important predictor for the presence of microvascular complications like diabetic nephropathy, retinopathy and neuropathy. ${ }^{29}$

In this study there was a significant difference in NLRatio comparison with respect to vascular complications in patients with Type 2 DM. Thus, this study highlighted the importance of a routine assessment of NeutrophilLymphocyte ratio which can be easily calculated from a simple peripheral blood count in patients with diabetes to predict the vascular complications.

\section{CONCLUSION}

From this study we can conclude that NLR is significantly increased in diabetic patients with complications compared to diabetics without complications showing that increment is more in diabetics with poor glycemic control and longer duration of the disease. NLR would be a useful marker of vascular complications in diabetes both micro and macrovascular. Hence, it can be shown that NLR can be used as a simple and cost-effective tool to monitor the progression and control of DM and its vascular complications.

\section{ACKNOWLEDGEMENT}

Authors would also like to thank Dr Ravi K, HOD \& Prof. Department of Medicine, BMCRI and are grateful to all the patients who participated in the study.

\section{REFERENCES}

1. Kahm K, Laxy M, Schneider U, Rogowski WH, Lhachimi SK, and Holle R. Health care costs associated with incident complications in patients with type 2 diabetes in Germany. Diabetes Care. 2018; 41(5): 971-978.

https://doi.org/10.2337/dc17-1763

2. Cho NH, Shaw JE, Karuranga S, Huang $\mathrm{Y}$, da Roncha Fernandes JD, Ohlrogge AW, et al. IDF Diabetes Atlas: global estimates of diabetes prevalence for 2017 and projections for 2045. Diabetes Research and Clinical Practice. 2018; 138: 271-281. https://doi.org/10.1016/j.diabres.2018.02.023

3. Garber AJ, Abrahamson MJ, Barzilay JI, Mechanick JI, Rosenblit PD, Umpierrez GE, et al. Consensus statement by the 
American Association of Clinical Endocrinologists and American College of Endocrinology on the comprehensive type 2 diabetes management algorithm - 2019 executive summary. Endocrine Practice. 2019; 25(1): 69-100.

https://doi.org/10.4158/CS-2018-0535

4. Dutta D and Mukhopadhyay S. Intervening at prediabetes stage is critical to controlling the diabetes epidemic among Asian Indians. Indian J Med Res. 2016; 143(4):401-404.

https://doi.org/10.4103/0971-5916.184281

5. Ferrucci $L$ and Fabbri $E$. Inflamm ageing: chronic inflammation in ageing, cardiovascular disease, and frailty. Nature Reviews. Cardiology. 2018; 15(9): 505-522.

https://doi.org/10.1038/s41569-018-0064-2

6. Fujita T, Hemmi S, Kajiwara M, Yabuki M, Fuke Y, Satomura A, et al. Complement-mediated chronic inflammation is associated with diabetic microvascular complication. Diabetes/Metabolism Research and Reviews. 2013; 29(3): 220-226.

https://doi.org/10.1002/dmrr.2380

7. Cebeci E, Cakan C, Gursu M, Uzun S, Karadag S, Koldas M, et al. The main determinants of serum resistin level in type 2 diabetic patients are renal function and inflammation not presence of microvascular complication, obesity and insulin resistance. Experimental and Clinical Endocrinology \& Diabetes. 2019; 127(4): 189-194.

https://doi.org/10.1055/s-0043-121262

8. Twig G, Afek A, Shamiss A, Derazne E, Tzur D, Gordon B, et al. White blood cells count and incidence of type 2 diabetes in young men. Diabetes Care. 2013; 36:276-282.

https://doi.org/10.2337/dc11-2298

9. Jiang $\mathrm{H}$, Yan WH, Li CJ, Wang AP, Dou JT and Mu YM. Elevated white blood cell count is associated with higher risk of glucose metabolism disorders in middle-aged and elderly Chinese people. Int J Environ Res Public Health. 2014; 11:5497-509.

https://doi.org/10.3390/ijerph110505497

10. Vozarova B, Weyer C, Lindsay RS, Pratley RE, Bogardus C and Tataranni PA. High white blood cell count is associated with a worsening of insulin sensitivity and predicts the development of type 2 diabetes. Diabetes. 2002; 51:455-461.

https://doi.org/10.2337/diabetes.51.2.455

11. Horne BD, Anderson JL, John JM, Weaver A, Bair TL, Jensen KR, et al. Which white blood cell subtypes predict increased cardiovascular risk? J Am Coll Cardiol. 2005; 45:1638-1643 https://doi.org/10.1016/j.jacc.2005.02.054

12. Choudhuri S, Dutta D, Sen A, Chowdhury IH, Mitra B, Mondal LK, et al. Role of $\mathrm{N}-\varepsilon$ - carboxy methyl lysine, advanced glycation end products and reactive oxygen species for the development of nonproliferative and proliferative retinopathy in type 2 diabetes mellitus. Mol Vis. 2013; 19:100-113.

https://doi.org/10.1016/j.diabres.2013.03.031

13. Choudhuri S, Chowdhury IH, Das S, Dutta D, Saha A, Sarkar R, et al. Role of NF-KB activation and VEGF gene polymorphisms in VEGF up regulation in non-proliferative and proliferative diabetic retinopathy. Mol Cell Biochem. 2015; 405:265-279. https://doi.org/10.1007/s11010-015-2417-z

14. Choudhuri S, Mandal LK, Paine SK, Sen A, Dutta D, Chowdhury $\mathrm{IH}$, et al. Role of hyperglycemia-mediated erythrocyte redox state alteration in the development of diabetic retinopathy. Retina. 2013; 33:207-216.

https://doi.org/10.1097//AE.0b013e318256202e

15. Mandal LK, Choudhuri S, Dutta D, Mitra B, Kundu S, Chowdhury IH, et al. Oxidative stress-associated neuroretinal dysfunction and nitrosative stress in diabetic retinopathy. Can J Diabetes. 2013; 37:401-407.

https://doi.org/10.1016/j.jcjd.2013.05.004

16. Choudhuri S, Dutta D, Chowdhury IH, Mitra B, Sen A, Mandal LK, et al. Association of hyperglycemia mediated increased advanced glycation and erythrocyte antioxidant enzyme activity in different stages of diabetic retinopathy. Diabetes Res Clin Pract. 2013; 100:376-384.

https://doi.org/10.1016/j.diabres.2013.03.031

17. Nguyen DV, Shaw LC and Grant MB. Inflammation in the pathogenesis of microvascular complications in diabetes. Front Endocrinol (Lausanne). 2012; 3:170 https://doi.org/10.3389/fendo.2012.00170

18. Rajala MW, Scherer PE. Minireview: The adipocyte - At the crossroads of energy homeostasis, inflammation, and atherosclerosis. Endocrinology. 2003; 144:3765-3773. https://doi.org/10.1210/en.2003-0580

19. Dutta D, Choudhuri S, Mondal SA, Maisnam I, Reza AH, Ghosh S, et al. Tumor necrosis factor alpha -238G/A (rs 361525) gene polymorphism predicts progression to type-2 diabetes in an Eastern Indian population with prediabetes. Diabetes Res Clin Pract. 2013; 99: e37-e41. https://doi.org/10.1016/j.diabres.2012.12.007

20. Rudiger A, Burckhardt OA, Harpes P, Müller SA and Follath F. The relative lymphocyte count on hospital admission is a risk factor for long-term mortality in patients with acute heart failure. Am J Emerg Med. 2006; 24:451-454. https://doi.org/10.1016/j.ajem.2005.10.010

21. Bhutta H, Agha R, Wong J, Tang TY, Wilson YG and Walsh SR. Neutrophil-lymphocyte ratio predicts medium-term survival following elective major vascular surgery: A cross-sectional study. Vasc Endovascular Surg. 2011; 45:227-231. https://doi.org/10.1177/1538574410396590

22. Turkmen K, Guney I, Yerlikaya FH and Tonbul HZ. The relationship between neutrophil-to-lymphocyte ratio and inflammation in endstage renal disease patients. Ren Fail. 2012; 34:155-159. https://doi.org/10.3109/0886022X.2011.641514

23. [Guideline] American Diabetes Association. Summary of Revisions: Standards of Medical Care in Diabetes-2020. Diabetes Care. 2020 Jan. 43 (Suppl 1): S4-S6. https://doi.org/10.2337/dc20-Srev

24. Grading diabetic retinopathy from stereoscopic color fundus photographs - An extension of the modified Airlie House classification. ETDRS report number 10. Early Treatment Diabetic Retinopathy Study Research Group. Ophthalmology. 1991;98(5 Suppl):786-806. https://doi.org/10.1016/S0161-6420(13)38012-9

25. IDF Diabetes Atlas [Internet]. Idf.org. [cited 2020 Dec 12]. Available from: https://www.idf.org/e-library/epidemiologyresearch/diabetes-atlas.html

26. Haghighatpanah $M$, Thunga $G$, Khare $S$ and Mallayasamy $S$. Correlation of glycosylated hemoglobin levels with fasting and postprandial glucose in South Indian type 2 diabetic patients. Int J Pharm Pharm Sci. 2016;8(8):285-288. 10.22159/ajpcr.2017. v11i1.22533

27. Chittawar S, Dutta D, Qureshi Z, Surana V, Khandare S and Dubey TN. Neutrophil-lymphocyte ratio is a novel reliable predictor of nephropathy, retinopathy, and coronary artery disease in Indians with type-2 diabetes. Indian J Endocr Metab. 2017; 21:864-870.

https://doi.org/10.4103/ijem.IJEM_476_16 
28. Hussain $M$, Babar MZM, Akhtar $L$ and Hussain MS Neutrophil lymphocyte ratio (NLR): A well assessment tool of glycemic control in type 2 diabetic patients. Pak J Med Sci. 2017;33(6):1366-1370.

https://doi.org/10.12669/pjms.336.12900
29. Moursy EY, Megallaa MH, Mouftah RF and Ahmed SM. Relationship between neutrophil lymphocyte ratio and microvascular complications in Egyptian patients with type 2 diabetes. Am J Intern Med. 2015;3(6):250-255.

https://doi.org/10.11648/j.ajim.20150306.16

\section{Author's Contribution:}

STA - Concept and design of the study; coordination; SHK - Interpreted the results; reviewed the literature and manuscript preparation; RKR - Review of literature and manuscript preparation; coordination; RMG - Prepared first draft of manuscript Statistically analyzed and interpreted, preparation of manuscript and revision of the manuscript.

\section{Work Attributed to:}

Bangalore Medical College and Research, Bangalore, Karnataka, India

Orcid ID:

Dr. Shilpa Tumkur Andane Gowda - (1) https://orcid.org/0000-0001-9610-7520

Dr. Shahari Hegde Kusumakar - (i) https://orcid.org/0000-0002-0158-6117

Dr. Raveendra Kodur Ramamurthy - (i) https://orcid.org/0000-0003-4246-9491

Dr. Rohith Maraludevanapura Govindaiah - (1) https://orcid.org/0000-0003-3915-9521

Source of funding: None, Conflict of Interest: None. 